\title{
Mapping of penetrometer resistance in relation to tractor traffic using multivariate geostatistics
}

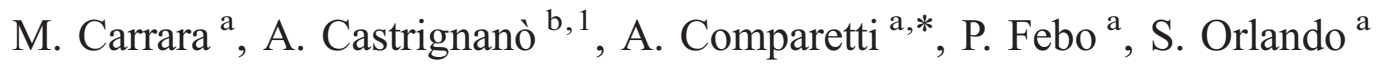 \\ a Dipartimento I.T.A.F., Università di Palermo, Viale delle Scienze, Building 4, 90128, Palermo, Italy \\ ${ }^{\mathrm{b}}$ CRA - Istituto Sperimentale Agronomico, Via Celso Ulpiani, 5, 70125, Bari, Italy
}

Received 9 June 2006; received in revised form 30 March 2007; accepted 22 August 2007

Available online 1 October 2007

\begin{abstract}
The traffic of agricultural machines can cause soil compaction and high variability of soil structure, both along normal lines and along those parallel to the field plane. The aim of this work was to investigate the potential of an electronic penetrometer, a GPS, a GIS and geostatistical techniques for mapping soil compaction.

In July 2003 soil cone penetrometer resistance was measured using a semi-automatic electronic penetrometer in a sandy-silt soil (Vertic Xerochrept) of inland Sicily where a three-year rotation wheat (Triticum durum Desf.)-wheat-tomato (Solanum lycopersicum L.) was practiced. The measurements were carried out along three parallel 3-m long transects, from the soil surface to a depth of $0.70 \mathrm{~m}$.

A multivariate geostatistical approach, including exploratory analysis, variography, stochastic simulation and post-processing of simulations, was applied to produce thematic maps of penetrometer resistance and probability exceeding a critical value, in correspondence of a different number of tractor passes. Penetrometer resistance variation resulted erratic at the surface but showed high spatial correlation between data measured at different depths. The probabilistic maps of compaction risk showed that the soil volume, exceeding the penetrometer resistance of $2.5 \mathrm{MPa}$, critical for root growth, at the probability level of $p>0.40$ increased from $20 \%$ to $40 \%$ after five tractor passes.
\end{abstract}

(C) 2007 Elsevier B.V. All rights reserved.

Keywords: Soil compaction mapping; Cone penetrometer resistance; Multivariate geostatistics; Joint stochastic simulation

\section{Introduction}

The implementation of intensive agricultural production systems has led to the use of heavy machines with high working capacity requiring high traction forces. The traffic of these machines can cause soil compaction and general structural degradation, reducing porosity and creating obstacles to air, water, nutrient movements and root penetration (Carrara et al., 2003; Febo and Pessina, 2002). Soil compaction can result in an increase of natural soil density even at shallow depth (at 0 $0.50 \mathrm{~m}$ ), where the elongated pores distributed along lines

\footnotetext{
* Corresponding author. Fax: +39091484035.

E-mail addresses: mcarrara@unipa.it (M. Carrara), annamaria.castrignano@entecra.it (A. Castrignanò), comparetti@unipa.it (A. Comparetti),pierfebo@unipa.it (P. Febo), santo.orlando@unipa.it (S. Orlando).

${ }^{1}$ Tel.: +39080 5475023 .
}

parallel to the field plane are prevalent on those distributed normally to the field plane itself, which are relevant for water drainage (Febo et al., 1998). Repeated passes on the field can then cause pans, having a low permeability to water and nutrients and a high resistance to root penetration. Plant root characteristics, such as diameter, elongation and morphology, are negatively affected by high values of soil cone penetrometer resistance caused by soil compaction (Atwell, 1990) and there are several examples of the negative effect of soil compaction on crop production (Taylor et al., 1966; Heinonen et al., 2002). When erroneous field management causes soil compaction, a reduction of crop yield is observed during both the current crop season and the subsequent ones (Oussible et al., 1992).

To understand whether a field is subjected or not to soil compaction, the farmer should reply to questions about intensity, extension, spatial and temporal variation, depth, thickness and time of compaction, which require a site-specific investigation across the field itself. Only a proper local survey 
and an adequate mapping of the compacted areas enable successful soil tillage, because the tillage depth can be optimised according to the compaction depth. Variable depth tillage could be applied by working just beneath the compacted layer and only where it is necessary (Basso et al., 2003). Therefore, fuel, labour, equipment wear and tear could be saved by farmers.

The measurement of cone penetrometer resistance is an easy, quick and cheap empirical method, widely used for monitoring and assessing soil compaction (Pagliai et al., 2000; Castrignanò et al., 2002a). Bengough and Mullins (1990) assumed that the soil strength measured by a penetrometer is equal to the pressure encountered by roots during growth. Other authors (Bennie, 1991; Bathke et al., 1992) verified that root elongation stopped where cone penetrometer resistance values range from 0.8 to $5 \mathrm{MPa}$. Therefore, readings up to $5 \mathrm{MPa}$ can be assumed as an indication of compacted soils, which impede root growth and negatively affect crop yield. In the past hand held penetrometers have been primarily used for trouble shooting. The accuracy of the measurement is highly related to the ability to push the penetrometer probe into the surveyed soil layer at a constant speed, even if it is almost impossible. Moreover, collecting enough data across a whole field, so that geo-referenced maps of soil compaction can be produced, takes a long time, is expensive and often not convenient. Nowadays it is possible to map the within-field soil compaction by using an electronic penetrometer. It is constituted by a rod, ending with a cone, pushed into the soil by a hydraulic cylinder, a load cell measuring the applied force and a displacement detector measuring the penetration depth. The collected data, together with the related positions, sensed by a GPS, can be transferred to a PC, where a Geographic Information System (GIS) processes them, in order to produce soil compaction maps. Thus the farmer can observe how soil compaction is variable at different depths and across the field. The soil compaction maps can provide two types of information: the values of soil cone penetrometer resistance; the field areas and the depth where eventually soil compaction occurs.

The intensity and distribution of the traffic of agricultural machines may actually cause a high $3 \mathrm{D}$ variability of soil structure, even in soils characterised by spatial homogeneity of physical properties (Castrignanò et al., 2001; Mouazen et al., 2001). Spatial variability of soil cone penetrometer resistance is significantly affected by machine traffic, which generates compacted soil volumes located under the wheel tracks (Richard et al., 1999) and, therefore, generally causes heterogeneity of soil physical properties (Castrignanò et al., 2002a, 2003). As the traffic effect is spatially variable, it is necessary to carry out geo-referenced soil cone penetrometer resistance measurements, in order to describe the spatial variation of soil compaction and its evolution over time as a consequence of successive machine passes. One approach is that of producing interpolated maps of cone penetrometer resistance values measured at different times, using the geostatistical technique of (co)kriging and then comparing the maps to each other, in order to detect the persistence or changes in spatial patterns over time (Goovaerts and Chiang, 1993; Castrignanò et al., 2002a).
Theoretically, (co)kriging provides the best estimates in the least square sense, because local error variance is minimal. However, this method usually overestimates low values and underestimates high values (Goovaerts, 1997) and provides estimation variance depending only on data configuration (homoskedasticity of variance) but not on the actual values of data. On the contrary, stochastic simulation allows the production of maps showing the spatial variability without smoothing (Deutsch and Journel, 1998; Castrignanò et al., 2002b). In each location the simulation algorithms calculate many values, which can then be used to obtain expected predictions and variances. Moreover, the variances very often change over space, depending not only on data configuration but also on data values (heteroskedasticity of variance) and, therefore, (co)kriging variance cannot be used to adequately assess local uncertainty. This last estimation is quite critical in decision making aimed at site-specific field management: defining a soil as a compacted one and, therefore, carrying out the appropriate action of recovery implies a set of problems, because any estimate of soil properties is affected by uncertainty (Goovaerts, 2001). Geostatistical simulation is an advanced methodology for quantifying spatial distribution of soil cone penetrometer resistance and the related uncertainty in assessing soil compaction. From the set of alternative equally probable outcomes at each node of the simulation grid the local distribution function of soil cone penetrometer resistance can be obtained and then the probability of exceeding a certain critical threshold for rooting can be computed. The latter can be considered as a probabilistic measurement of compaction risk at any location. The measurements carried out by using the

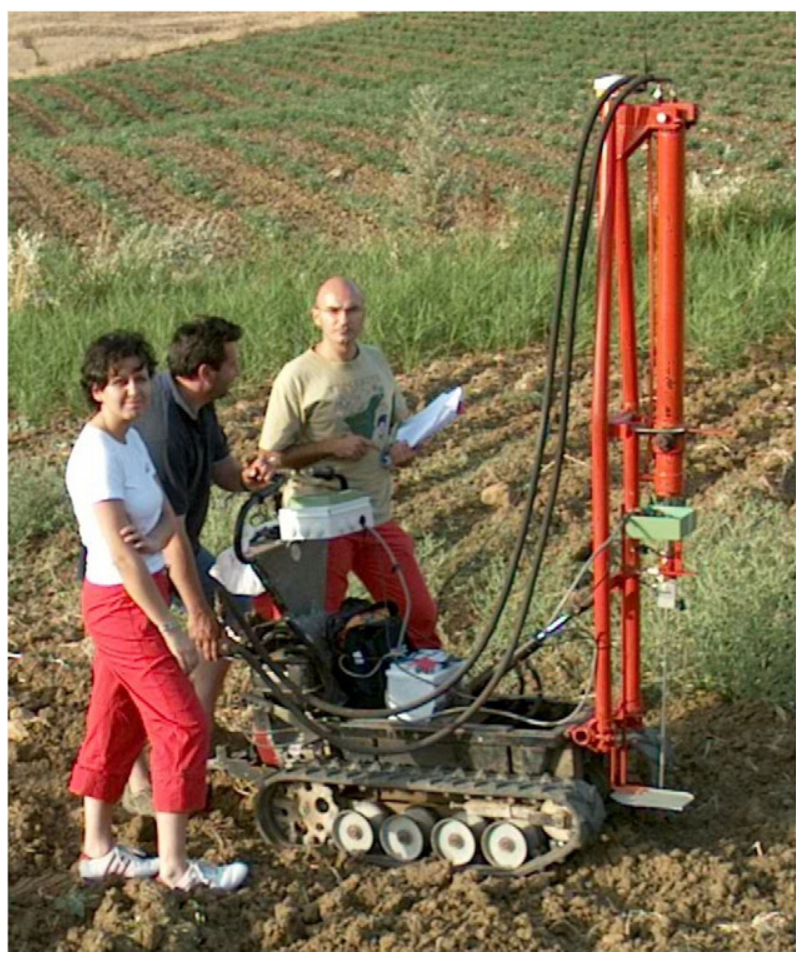

Fig. 1. The system for the geo-referenced measurement of soil cone penetrometer resistance used during the tests. 


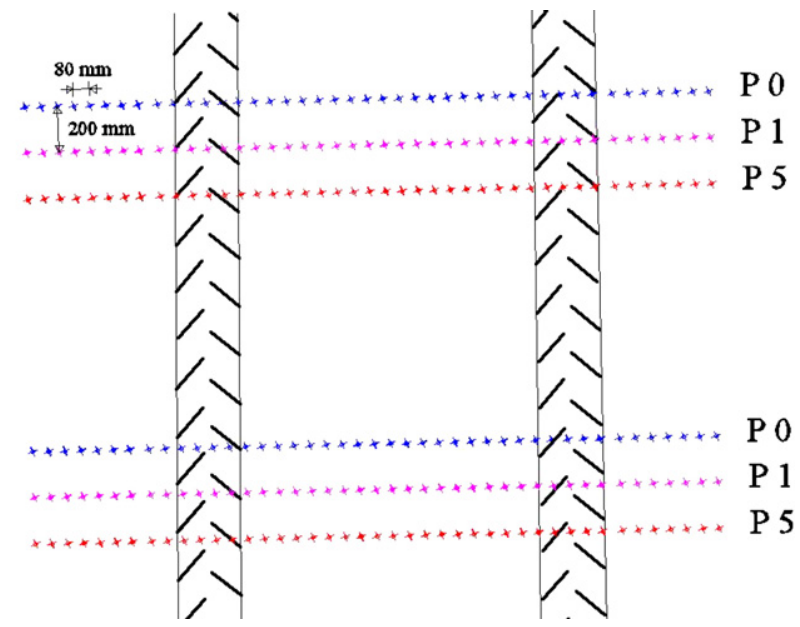

Fig. 2. Map showing the three parallel 3-m long transects of soil cone penetrometer resistance measurements and the tractor wheel tracks. Measurements were taken after zero (P0), one (P1) and five (P5) passes of the tractor.

electronic penetrometer, combined with advanced geostatistical methods, may then provide farmers with information about both the compacted areas and the soil compaction depth, in order to apply recovery measures only in those areas and, therefore, minimise their cost.

The aim of this research was to investigate the potential of an electronic penetrometer, a GPS, a GIS and the application of geostatistical techniques, in order to map and assess the spatial variability of soil compaction caused by repeated passes of agricultural machines.

\section{Materials and methods}

\subsection{Measurement equipment}

During the tests a system for the geo-referenced measurement of soil cone penetrometer resistance mounted on a tracked minitransporter, Rotair Rampicar R-600, was used (Carrara et al., 2005). It consisted of the following instruments (Fig. 1):

- an electronic penetrometer, Eijkelkamp Penetrologger 06.15, consisting of a load cell, an ultrasonic depth sensor, a data logger and a probing rod, ending with a cone of $200-\mathrm{mm}^{2}$ base area (according to the ASAE standard 313.1); this instrument can measure a penetration force ranging from 0 to $1000 \mathrm{~N}$ (with a resolution of $1 \mathrm{~N}$ ) up to a maximum depth of $0.80 \mathrm{~m}$ (with a resolution of $10 \mathrm{~mm}$ ) and display cone penetrometer resistance data;
- an L1/L2 DGPS mobile receiver, Scorpio 6502 MK from DSNP (now Thales Navigation), connected to a data logger, Husky MP2500, with a built-in UHF radio receiver, for receiving in real time the differential correction signals from a UHF radio transmitter, connected to a base station, DSNP Scorpio 6502 SK.

In order to lower or lift the penetrometer at a constant speed, it was mounted onto a hydraulic cylinder, which was fitted to a specifically built metal frame, joined to the minitransporter. It was possible to adjust the inclination of this frame by means of another hydraulic cylinder, so that the force applied by the penetrometer to the soil and the penetration direction were normal to the field plane.

This system, requiring only one operator and able to climb over sloping ground, has a total mass of $400 \mathrm{~kg}$, a total contact surface of $0.288 \mathrm{~m}^{2}$, a soil ground pressure of $0.013 \mathrm{MPa}$, a length of $1.5 \mathrm{~m}$ and a width of $0.80 \mathrm{~m}$ and, therefore, a small turning space. With respect to manual penetrometers, this system provides the following advantages: it highly decreases measurement time, keeps a constant penetration speed, applies a force normal to the field plane and allows the measurement and recording of geo-referenced cone penetrometer resistance data.

\subsection{Area description}

In July 2003 the measurement tests were carried out in a field located at Alia (Palermo, Italy, latitude $37^{\circ} 46^{\prime} 18^{\prime \prime} \mathrm{N}$, longitude $13^{\circ} 42^{\prime} 29^{\prime}$ ' E, altitude $860 \mathrm{~m}$ above s.l. ca., annual mean temperature $14.5^{\circ} \mathrm{C}$ and annual mean precipitation $450 \mathrm{~mm}$ ), where a three-year rotation wheat (Triticum durum Desf.)-wheattomato (Solanum lycopersicum L.) was practiced (2003 was the third year). The soil is a Vertic Xerochrept (USDA, 1998), with a sandy-silt texture (clay $8 \%$, silt $33.7 \%$ and sand $58.3 \%$ ) and a moisture of $4.9 \%$ (constant during the whole testing day).

Before the tests the soil was ploughed at a depth of $0.35-\mathrm{m}$ (in August 2002) and harrowed at 0.10-m depth (in October 2002, February and April 2003).

\subsection{Methods for measuring geo-referenced soil cone pen- etrometer resistance}

As the testing field was mostly flat, the field plane was perpendicular to the vertical line, so that only a toric level was needed to ensure that the penetrometer was vertical and, therefore, normal to the field plane. Thus, the relative positioning was maintained along the whole penetration. Geo-referenced soil cone penetrometer resistance was measured from the soil

Table 1

Basic statistics of soil cone penetrometer resistance (MPa) measured after zero (P0), one (P1) and five (P5) passes of the tractor

\begin{tabular}{|c|c|c|c|c|c|c|c|c|c|}
\hline Variable & Count & Minimum & Maximum & Mean & Median & Standard deviation & Variance & Skewness & Kurtosis \\
\hline P0 & 2378 & 0.090 & 5.00 & 1.93 & 1.61 & 1.57 & 2.45 & 0.95 & 3.05 \\
\hline P1 & 2098 & 0.10 & 5.00 & 1.88 & 1.50 & 1.52 & 2.31 & 1.11 & 3.37 \\
\hline P5 & 2238 & 0.15 & 3.96 & 2.40 & 1.95 & 1.69 & 2.86 & 0.64 & 2.30 \\
\hline
\end{tabular}


Table 2

Fitted linear model of co-regionalization of the normal scores (G0, G1, G5) of the corresponding soil penetrometer resistance variables (MPa)

\begin{tabular}{|c|c|c|c|c|c|c|c|c|}
\hline & Model & Variable & G0 & G1 & G5 & Eigen.1 & Eigen. 2 & Eigen. 3 \\
\hline \multirow[t]{3}{*}{$\mathrm{a}$} & Horizontal spherical $($ range $=0.50 \mathrm{~m})$ & G0 & 0.5729 & 0.0972 & -0.0155 & 0.6256 & 0.4344 & 0.3566 \\
\hline & & G1 & 0.0972 & 0.4463 & 0.0358 & $(44.16 \%)$ & $(30.67 \%)$ & $(25.17 \%)$ \\
\hline & & G5 & -0.0155 & 0.0358 & 0.03974 & & & \\
\hline \multirow[t]{3}{*}{$\mathrm{b}$} & Vertical cubic $($ range $=0.20 \mathrm{~m})$ & G0 & 0.4556 & 0.13267 & 0.1318 & 0.5465 & 0.1443 & 0.0452 \\
\hline & & G1 & 0.1326 & 0.0947 & 0.0170 & $(74.26 \%)$ & $(19.60 \%)$ & $(6.14 \%)$ \\
\hline & & G5 & 0.1318 & 0.0170 & 0.1856 & & & \\
\hline \multirow[t]{3}{*}{$\mathrm{c}$} & Vertical Bessel-K (range $=1 \mathrm{~m})$ & G0 & 2.3105 & 4.1764 & 3.7675 & 16.3079 & 0.4171 & 0.00 \\
\hline & & G1 & 4.1764 & 7.5499 & 6.8333 & $(97.51 \%)$ & $(2.49 \%)$ & $(0 \%)$ \\
\hline & & G5 & 3.7675 & 6.8333 & 6.8646 & & & \\
\hline
\end{tabular}

The co-regionalization matrices, related to the three basic structures, and the corresponding Eigen values and the variance percentages (within parenthesis) are shown. The Eigen vectors are computed from the variance-covariance matrix of three variables (G0, G1 and G5) and define the main directions of the 3D cloud made by the values of the variables. These directions are orthogonal and successively explain a decreasing part of the total variability of the cloud, from the first direction, explaining the largest part of the variability, to the last direction, explaining the lowest part of the variability. Each Eigen vector is defined as a linear combination of the variables and is associated with an Eigen value, equal to its variance and to the part of the total variability that this Eigen vector explains.

surface to a depth of $0.70 \mathrm{~m}$, with a depth resolution of $10 \mathrm{~mm}$. Preliminary random tests were carried out, in order to determine the minimum distance at which there was no interaction between adjacent measurements, so that the eventual differences of cone penetrometer resistance were due only to spatial variability. This distance was found to be $70 \mathrm{~mm}$.

In order to study and evaluate the effects of the traffic of agricultural machines on soil compaction, a $58-\mathrm{kW}$ four wheel drive tractor FIAT 766 DT, with a mass of $3340 \mathrm{~kg}$, was used on the testing field. The tractor front axle was fitted with 13.6 R24 tyres and its rear axle with 16.9 R34 tyres; all tyres were inflated at the pressure recommended by the manufacturer of $120 \mathrm{kPa}$.

The soil cone penetrometer resistance data were measured along three parallel 3-m long transects, $200 \mathrm{~mm}$ apart from each other, containing the tractor wheel tracks, in three testing conditions: after zero (P0), one (P1) and five (P5) passes of the tractor (Fig. 2). These conditions simulated the undisturbed soil, the soil compacted by minimum traffic and the soil compacted by heavy traffic (Pagliai et al., 2000; Carrara et al., 2003). The measurement tests were carried out within one day, so that the soil water content was assumed approximately constant during the considered time interval.

During the tests the DGPS mobile receiver logged real time differentially corrected positions, $80 \mathrm{~mm}$ between each other, with an RMS accuracy of $\pm 0.010 \mathrm{~m}+0.5 * 10^{-6} \mathrm{~m}$.

The positions were processed using the Kinematic Interface Survey Software (KISS), while the cone penetrometer resistance data measured in each point were processed and displayed using Eijkelkamp PenViewer software.

\subsection{Multivariate geostatistical techniques}

In order to assess soil cone penetrometer resistance data on a localised basis, a multivariate geostatistical approach was applied. According to this method, the set of $T$ sampled times (P0, P1, P5) is viewed as a realisation of $T$ inter-correlated random functions. The simulation of the penetrometer resistance involves fitting a Linear Model of Co-regionalization or LMC (Goovaerts, 1997) to the $T(T+1) / 2$ simple and crossvariograms, decomposing the $T$ co-regionalized variables into orthogonal components associated with different spatial scales (Castrignanò et al., 2002a,b). In this model each variable is expressed as linear combination of the same elementary spatial components and all simple and cross-variograms are then modelled as linear combinations of the same basic structures. The complete covariance model is expressed by the list of the nested normalised basic structures $($ sill $=1)$ and the matrices (square, symmetrical and having dimension equal to the number of variables) of the sills corresponding to each basic structure. Each of these matrices, called a co-regionalization matrix, is a positive semi-definite matrix, each element of which expresses the relative importance of the corresponding basic structure in modelling simple or cross-variogram. The multivariate approach was applied to the above soil cone penetrometer resistance data set, measured at three times, after none (P0), one (P1) and five (P5) passes of the tractor, which then constitute the set of the inter-correlated random functions.

Stochastic sequential simulation sequentially draws the value at each new simulated location from the conditional cumulative distribution function (ccdf), given the neighbouring sample data and the neighbouring values previously simulated (Chilès and Delfiner, 1999). A joint sequential simulation means simultaneous prediction of several variables; whereas cokriging allows to generate only one estimate for each variable in any location, the Monte-Carlo simulation allows to generate a set of $L$ joint realisations (or prediction maps) of $P$ variables. A realisation implies that each cell of the interpolation grid is provided with a vector of estimated variables. The ccdfs can be estimated in the simplest way by cokriging if a multi-Gaussian model is assumed for the multivariate distribution. If the data of the variables are not normally distributed, a normal score transformation must be performed, so that transformed data have normal distribution with zero means and unit variances. The simulation results must then be back-transformed to the raw distribution.

In this work each joint simulation was generated using a conditional sequential Gaussian simulation algorithm which simultaneously estimates all variables by cokriging (Chiles and Delfiner, 1999) at each node of a regularly spaced grid, covering the region of interest. This could be alternatively achieved by cokriging each variable from all the others at a time, but in this 
way a lot of CPU time would have been needed. A more efficient algorithm, used in this work, performed all calculations at a once and solved one linear system with $P$ right-hand sides rather than $P$ linear systems with one right-hand side (Chilès and Delfiner, 1999).

A random path through the grid was defined so that each node was visited only once (Deutsch and Journel, 1998; Castrignanò et al., 2002b). At each grid node to be visited, normal score transformed data values were used to determine the mean and variance of the conditional distribution function of each variable, given the neighbouring sample data and previous estimates, using cokriging. A value was drawn randomly from that distribution as a possible simulation in that location for each variable and this value was added to the conditioning data set; the calculation proceeded for the remaining variables and then shifted to the next node along the whole random path through the grid. Several simulations, virtually identical in their statistical character and differing only in the random-number seed used for initiating the simulation process, can be produced. However, the number of simulations needs to be determined. In this study 500 simulation runs were used, because this number made the global variance estimation stable. Joint sequential simulation was performed, using as co-variables the cone penetrometer resistance data measured after zero, one and five tractor passes.

Different types of statistical information were extracted from the set of back-transformed simulated images for each variable:

1) averaging the values for each pixel and producing the map of the "expected" value at any considered location (E-type or Expected-value estimate) (Journel, 1983), which, for a large enough number of realisations, can become similar to cokriging estimates;

2) calculating the standard deviation of the realizations for each pixel and producing the corresponding map, which was used as a measurement of uncertainty. Differently from the point one, this determination can sensibly differ from the cokriging standard deviation;

3) counting the number of times that each pixel exceeded a critical threshold value and converting the sum to a proportion, in order to produce a probability map of compaction risk; in our research the threshold value of $2.5 \mathrm{MPa}$ was selected, because this value was considered critical for root growth (Taylor et al., 1966).

\section{Results and discussion}

A preliminary explorative analysis of the soil cone penetrometer resistance measurements, based on the calculations of the traditional descriptive statistics, is presented in Table 1 . The soil cone penetrometer resistance spatially varied from a minimum of $0.09 \mathrm{MPa}$ to a maximum of $5 \mathrm{MPa}$, which is the maximum pressure measurable by the used penetrometer mounting the cone of $200-\mathrm{mm}^{2}$ base area. The maximum values were measured after five passes of the tractor. Also the spatial variance followed the same temporal pattern, even if it was less sensitive to the traffic effect. The $\chi^{2}$ test for normality was rejected for all testing conditions at a probability level lower than 0.05 and it was also confirmed by the highly positive values of the skewness parameter and the median values lower than the means. The kurtosis parameter showed a shift from normality (value of 3 ) only for the P5 distribution.

In order to highlight some significant persistence in soil compaction after successive tractor passes, the correlation coefficient between the measurements corresponding to the different testing conditions was used. The correlations ( $\mathrm{P} 0$ $\mathrm{P} 1=0.560 ; \mathrm{P} 0-\mathrm{P} 5=0.632 ; \mathrm{P} 1-\mathrm{P} 5=0.64)$ were always significant at probability level $p<0.01$ and tended to slightly increase as the number of the tractor passes increased. This might suggest that the soil tended to maintain its structure within at least five tractor passes, even if this assumption should be verified by more direct measurements on pore and aggregate distributions.

The above statistical parameters were calculated assuming that all soil cone penetrometer resistance measurements are mutually independent. However, measurements of soil cone penetrometer resistance which are made close to each other are frequently more similar than those made further apart (Burgess and Webster, 1980) and, therefore, provide expected values of soil cone penetrometer resistance which are spatially dependent (O'Sullivan et al., 1987). Spatial dependence was then taken into account by calculating the experimental simple and crossvariograms of the normal scores (G0, G1, G5) of the data recorded by the penetrometer at the same points in the three testing conditions (P0, P1, P5). Since in each testing condition all measurements lie on the surface within a narrow band including the three parallel transects, the directional variograms were calculated only along two main directions: 1$)$ the transect direction on the field plane ( $X$ axis); 2$)$ the direction orthogonal to the field plane ( $Z$ axis). The number of lags used to calculate the variograms was ten for both directions but the lag length was different: $0.15 \mathrm{~m}$ for $X$ axis and $0.03 \mathrm{~m}$ for $Z$ axis, due to the different resolution of the measurements along the two axes. A tolerance on direction of $15^{\circ}$ along both axes, due to the small support volume of penetrometer measurements, was selected.

A Linear Model of Co-regionalization (LMC) was then fitted to both simple and cross-variograms in a semi-automatic way: only the final tuning of the corresponding sills was automatically performed. The number, type, range and anisotropy of the basic spatial structures were previously chosen relying on the shape of the experimental variograms. The automatic sill fitting procedures aimed at minimising the distance between the experimental value of a variogram and the corresponding value of the model. Such a minimisation was performed giving different weights to different lags, so that the weight of each lag is directly proportional to the number of observation pairs and inversely proportional to the average distance of the lag, under

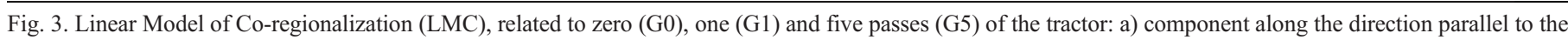
field plane; b) component along the direction orthogonal to the field plane. 
a)

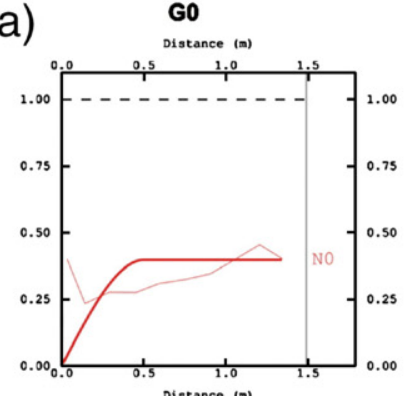

Distance (m)
Distance (m)

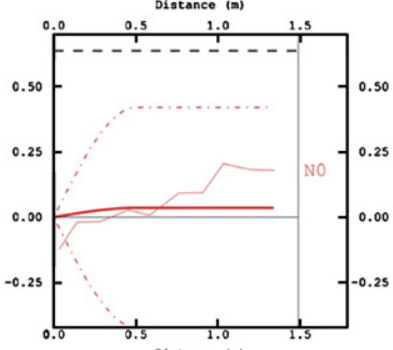

Distance $(\mathrm{m})$
Distance $(\mathrm{m})$

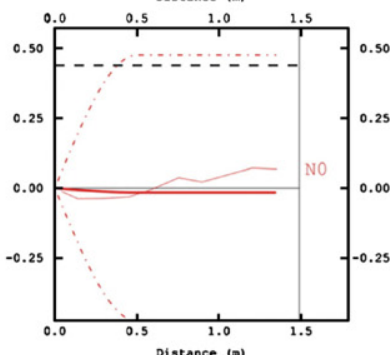

GO
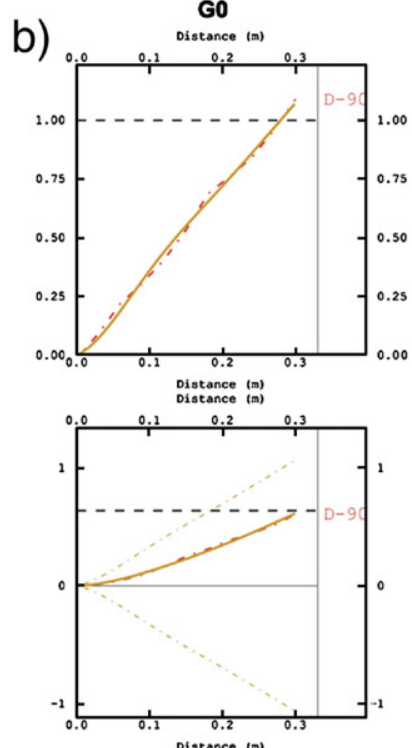

Distance (n)
oistance in

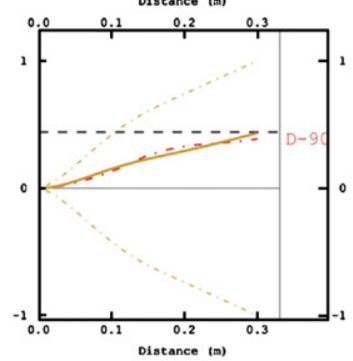

Bold line $=$ theoretical variogram

Thin line $=$ experimental variogram

Dashed line $=$ maximum spatial correlation
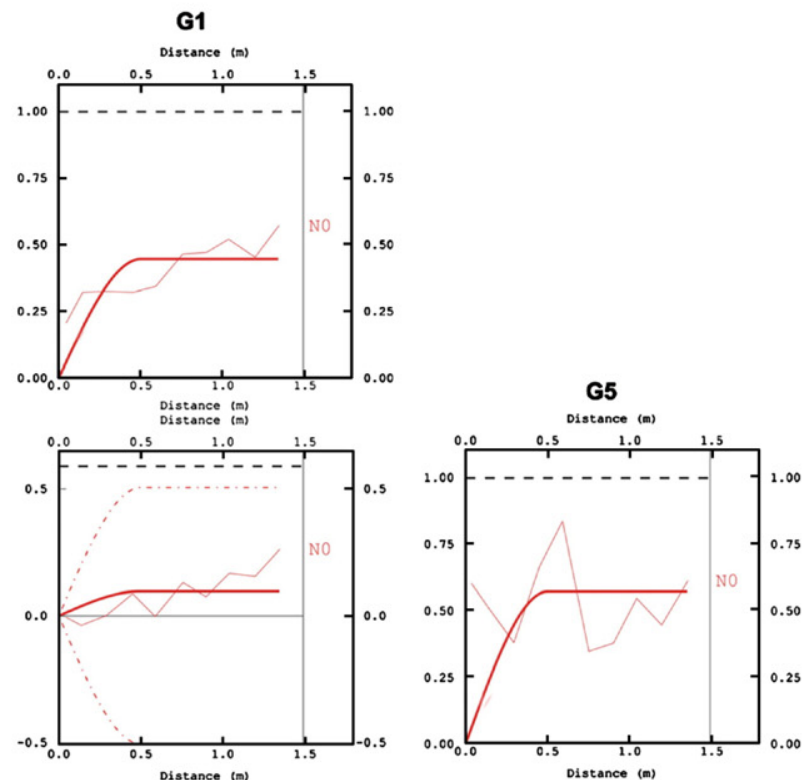
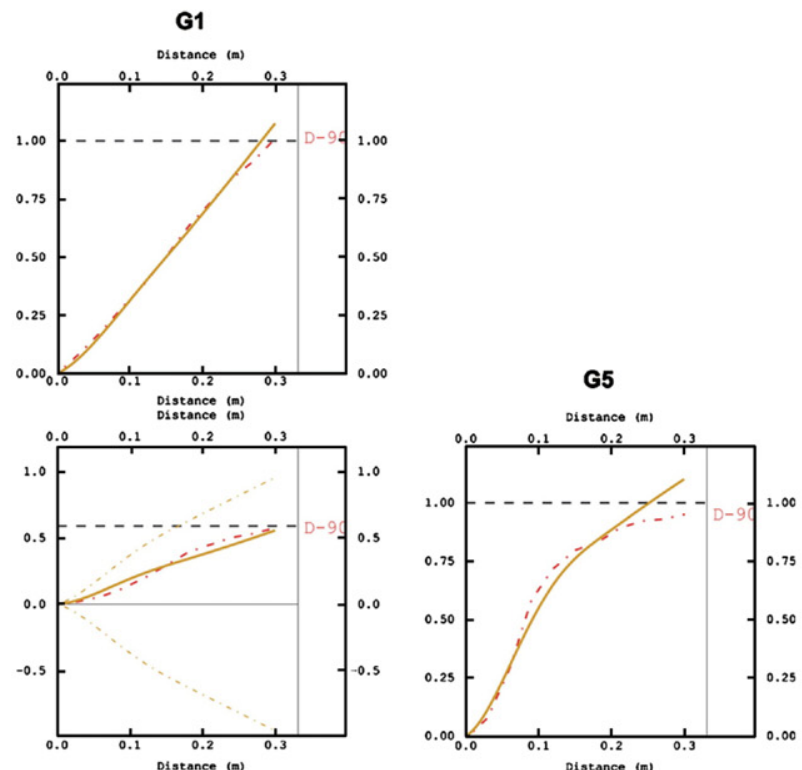

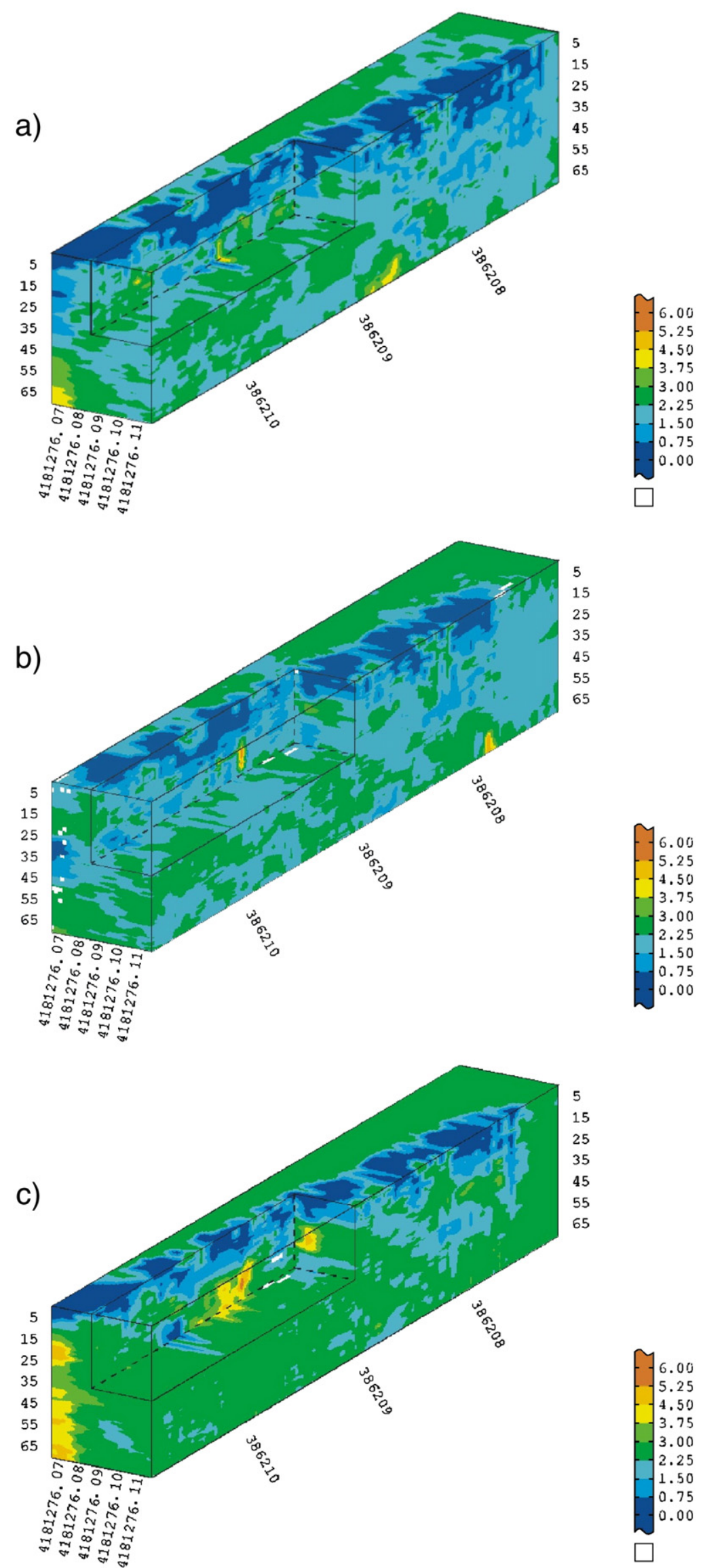

Fig. 4. 3D mean maps of the three back-transformed variables, related to zero (a), one (b) and five passes (c) of the tractor. 

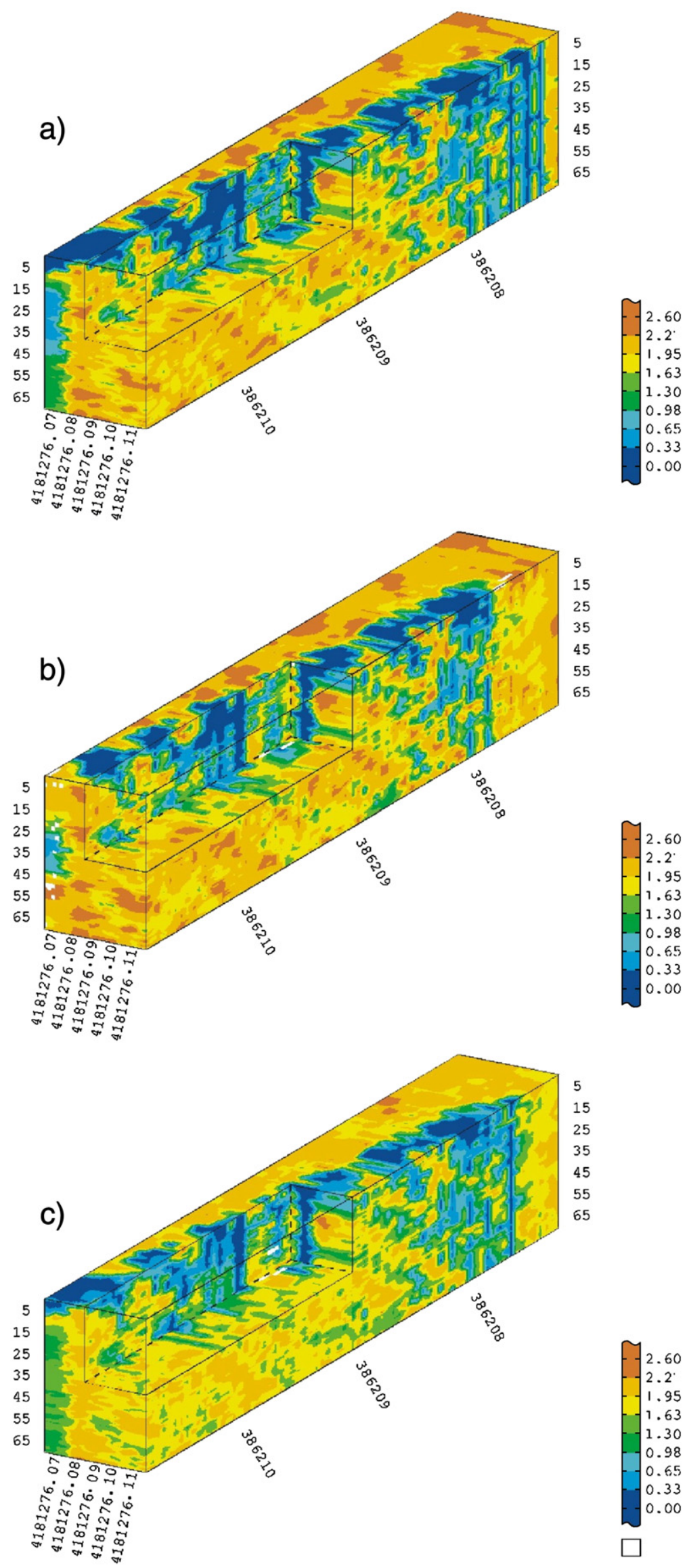

Fig. 5. 3D standard deviation maps of the three back-transformed variables, related to zero (a), one (b) and five passes (c) of the tractor. 

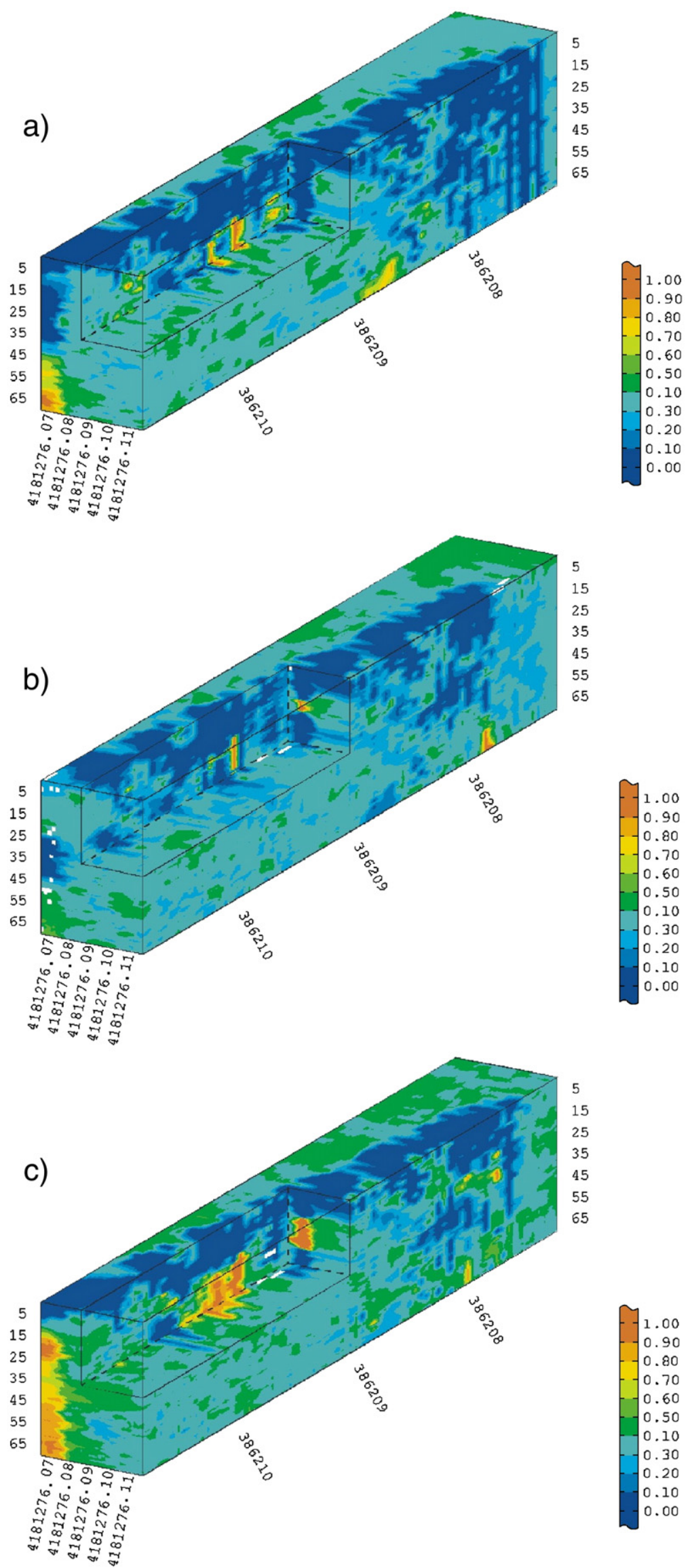

Fig. 6. 3D maps showing the probability of exceeding the threshold of soil cone penetrometer resistance, related to zero (a), one (b) and five passes (c) of the tractor. 
the constraints that each co-regionalization matrix is definite positive (Lajaunie and Béhaxétéguy, 1989).

The following three basic structures were used:

1. a directional spherical model, with a range of $0.50 \mathrm{~m}$ along the transect direction;

2. a directional cubic model, with a range of $0.20 \mathrm{~m}$ along the direction orthogonal to the field plane;

3. a bounded Bessel-k model (Chiles and Delfiner, 1999, pp. 638-639), with a range of $1.00 \mathrm{~m}$ and a parameter equal to 1 along the direction orthogonal to the field plane.

The multivariate model is presented in Table $2 \mathrm{a}, \mathrm{b}$, c, where the co-regionalization matrix is shown for each of the three basic structures, together with the corresponding Eigen values. These values show that most of spatial variability is related to the higher range variation along the direction orthogonal to the field plane (Bessel-k model). Moreover, using this spatial scale the three soil cone penetrometer resistance data sets resulted highly correlated, because the first Eigen value accounted for more than $97 \%$ of the total variance. This result means that the spatial structure tends to be conservative at higher depths.

If the diagonal values (variances) of the three co-regionalization matrices are considered, it is possible to observe that, as regards the short range variation, G0 shows the highest variance, both along the transect direction and the direction orthogonal to the field plane (Table $2 \mathrm{a}, \mathrm{b}$ ); on the contrary, as regards the high range variation, G1 and G5 show the highest variances along the direction orthogonal to the field plane (Table 2c). These results may suggest a progressive soil stratification, caused by the successive passes of the tractor.

The above results (Table 2c) show that the sills of the variogram models along the direction orthogonal to the field plane, having the higher range, do not reach the unit value; this fact seems to contradict the assumption that the transformed data have a standard Gaussian distribution with a unit variance. These results might be due, firstly, to stationarity defects, even if stationarity is a concept that depends on scale: the data can be stationary at a large scale, whereas at a small scale they look like non-stationary (Wackernagel, 2003, page 285). The variogram values show a spatial "trend" along the direction orthogonal to the field plane, owing to the limited surveyed soil depth. In this case the empirical distribution of the data set may differ from its theoretical distribution, related to its marginal distribution in an infinite domain. Since the depth of the sampled domain $(0.70 \mathrm{~m})$ is lower than the range of the variogram model $(1 \mathrm{~m})$, the dispersion or empirical variance is smaller than the variogram sill ("a priori" variance). Such an inequality is a consequence of Krige's relationship, according to which the dispersion or variance is lower than the theoretical one when the sampled field is not infinite (Chilès and Delfiner, 1999). Applying Gaussian anamorphosis, the empirical variance of the transformed data was set to one, whereas the "a priori" variance of the component along the direction orthogonal to the field plane with the longer range is greater. The spatial correlations between the samples located in a small surveyed domain may produce an apparent "trend", although they stem from a stochastic stationary process, involving a much higher volume (Chiles and Delfiner, 1999). In assessing the theoretical LMC variogram a first solution was tried by providing all sills with unit value. Yet, this solution contradicted the positive semidefinite condition of the co-regionalization matrices. Therefore, the adopted solution was to consider the variogram model up to a unit sill, since all the experimental values lie below this threshold (Fig. 3). Thus, all the stochastic images were constructed up to the maximum surveyed depth of $0.70 \mathrm{~m}$ and no extrapolation was tried.

The directional variogram models are shown in Fig. $3 \mathrm{a}, \mathrm{b}$ (continuous lines): the simple variograms along the transect (Fig. 3a) generally show an erratic behaviour; the random character of the component of the spatial variance along the transect also explains the missing or light cross-correlation between the horizontal components corresponding to the different testing conditions (cross-variograms). On the contrary, the computed cross-variograms of the vertical components of the spatial variance (Fig. 3b) are quite close to the upper dashed lines, which represent the maximum positive correlation. The simple variograms of the component plane of G0 and G1 along the direction orthogonal to the field look like unbounded, even if, for the above considerations, all the simple variograms were assumed bounded in the Linear Model of Co-regionalization, although at a range higher than the maximum depth surveyed. The apparent different behaviour of the G5 variogram, which looks like bounded, might suggest some ongoing change in soil structure. Successive passes of tractor might have disrupted most soil aggregates, causing spatial correlation length to decrease. In some cases the Linear Model of Co-regionalization is a raw approximation, because it assumes that the same basic structures can be fitted to the whole set of simple and crossvariograms. However, the assumption that for the considered soil no irreversible modification of structure occurred within five passes of tractor seems reasonable.

The above results suggest that the soil cone penetrometer resistance variation on layers parallel to the field plane is erratic and spatially correlated within very short distances (less than $0.50 \mathrm{~m}$ ). Therefore, measurements made more than $1 \mathrm{~m}$ apart from each other can be actually considered independent from each other. On the contrary, the soil cone penetrometer resistance data measured at different depths are spatially well structured and dependent on each other up to the highest surveyed depth $(0.70 \mathrm{~m})$.

Fig. 4a, b, c shows a way of treating the set of the simulated images of the three back-transformed variables, by calculating the mean of the 500 simulations produced at each grid node and, then, mapping the results for each variable. Because of the geometry of the surveyed soil volume, the $Y$ axis was distorted on the horizontal plane by a factor of 10 , in order to allow a better readability. The simulated 3D mean maps show that most variations were of an erratic type, with a slight stratification along the direction orthogonal to the field plane. The above results also reveal some differences between the eastern half of the surveyed soil volume and the western one, generally characterised by higher cone penetrometer resistance values, probably due to the intrinsic soil variation. The persistence of a 
compacted zone at a depth equal or lower than $0.40 \mathrm{~m}$ is visible, probably also due to the traditional tillage made every year at the same depth (ploughing pan). The three maps do not show clear differences in the spatial dependence structures; yet, a larger extension of the areas characterised by the highest values of soil cone penetrometer resistance can be detected in the last map. These maps give high density information of soil cone penetrometer resistance which, if combined with more sparsely data of other soil properties, could be efficiently used to assess soil compaction. However, the only mean maps are not sufficient to evaluate the soil compaction risk in site-specific management, because any estimate is inevitably affected by local uncertainty. Actually, the higher is the variation of local estimates of soil cone penetrometer resistance values the higher is the risk of planning soil tillage management relying only on soil compaction estimates. If the soil cone penetrometer resistance measurements were repeated on a grid, including a set of both longitudinal and transverse transects, the risk of soil compaction could be assessed in the whole field.

In Fig. 5a, b, c the standard deviation maps of soil cone penetrometer resistance corresponding to the different testing conditions are shown. These maps show a proportional effect between means and variances of the local distributions of simulated values, symptomatic of heteroskedastic soil cone penetrometer resistance variance, which confirms the uselessness, in this case, of cokriging variance as a measure of uncertainty.

Alternatively, the soil compaction risk can be expressed in probabilistic terms, calculating the probability of exceeding the critical value of soil cone penetrometer resistance $(2.5 \mathrm{MPa})$. The probability maps, corresponding to the different testing conditions (Fig. 6), were obtained by post-processing the 500 joint-simulated images of soil cone penetrometer resistance data and look like consistent with the mean maps (Fig. 4). Given a probability level, for example 0.40 , it is possible from the previous probability maps to identify the areas where the probability of exceeding the soil cone penetrometer resistance of 2.5 MPa is higher than this critical level. Fig. 7a, b shows these areas, respectively, after zero and one pass of the tractor: they are similar to each other and soil compaction distribution is characterised by some randomly distributed hot spots. The spatial pattern slightly changes after five tractor passes (Fig. 7c), due to an intensification and localisation of soil compaction, preferably along the western side of the transect. Since the 3D maps were produced in a GIS environment, it was also possible to calculate the portion of the surveyed soil at compaction risk after successive tractor passes, in order to produce a global indicator of soil compaction. The amount of soil at compaction risk was about $20 \%$ of the total soil volume at the beginning, remained approximately constant after one pass, but increased up to about $40 \%$ of the total after five passes.

The above results show that the traffic intensity may affect soil compaction and cause soil deformations, which worsen with an increasing number of tractor passes, as confirmed by several other authors (Bakker and Davis, 1995; Jorajuria and Draghi, 2000; Balbuena et al., 2000; Seker and Isildar, 2000). The main difficulty of the proposed approach for identifying compacted soil areas is to choose an appropriate probability threshold above which remedial action must be undertaken. Decision making is straightforward for the areas with a very high or very low probability, while it is much more difficult for the areas with intermediate probabilities, in the range $[0.30$ 0.70] (Goovaerts, 1999). Therefore, the choice of a probability threshold remains mainly subjective, mostly affected by land use and available financial resources. A more practical way of facing the problem is to assess the financial costs which might result from a wrong decision in tillage management and analyse different cost-effective solutions, also using simulation models.

\section{Conclusions}

This research has demonstrated the usefulness of an electronic penetrometer, used with a GPS, for sensing the depth and degree of the soil cone penetrometer resistance, as index of soil compaction, in the various surveyed positions of a field, and, then, producing 3D maps, by using a GIS software. These maps, showing the within-field spatial variability of soil compaction, can allow the managers and users of agricultural, forestry, environmental and ecological systems to assess the soil compaction itself and identify areas where site-specific soil management should be implemented. In fact, within these areas, the soil management practices could be varied, implementing, for example, no tillage or minimum tillage (subsoiling, etc.) or traditional tillage (ploughing and harrowing) with a variable working depth. Moreover, this research has proved that the decision process aimed at selecting the tillage system in any field area should be based not only on smooth interpolated maps, which might lead to a severe underestimation of soil compaction uncertainty and, therefore, of its economical and environmental impacts, but also on stochastic simulation. In fact, this geostatistical method allows to produce several maps showing the spatial variability of soil compaction, which can be used in order to assess the uncertainty in estimating soil compaction itself and its evolution as affected by the traffic of agricultural machines. The effect of such an uncertainty on the prediction of tillage costs could be evaluated using simulation models.

Another geostatistical method for assessing spatial uncertainty is to calculate the probability of exceeding some critical threshold of soil cone penetrometer resistance. The resulting probability maps can be used for assessing the soil compaction risk.

Indeed all the statistical and geostatistical methods used in this work are promising in the fields where the soil spatial variability suggests a soil management system on a localised basis, according to the principles of precision agriculture and, however, in all the fields, aiming at the soil conservation, according to the principles of sustainable agriculture.

Fig. 7. 3D maps showing the areas where the probability of exceeding the threshold of soil cone penetrometer resistance is higher than the critical level, related to zero (a), one (b) and five passes (c) of the tractor. 

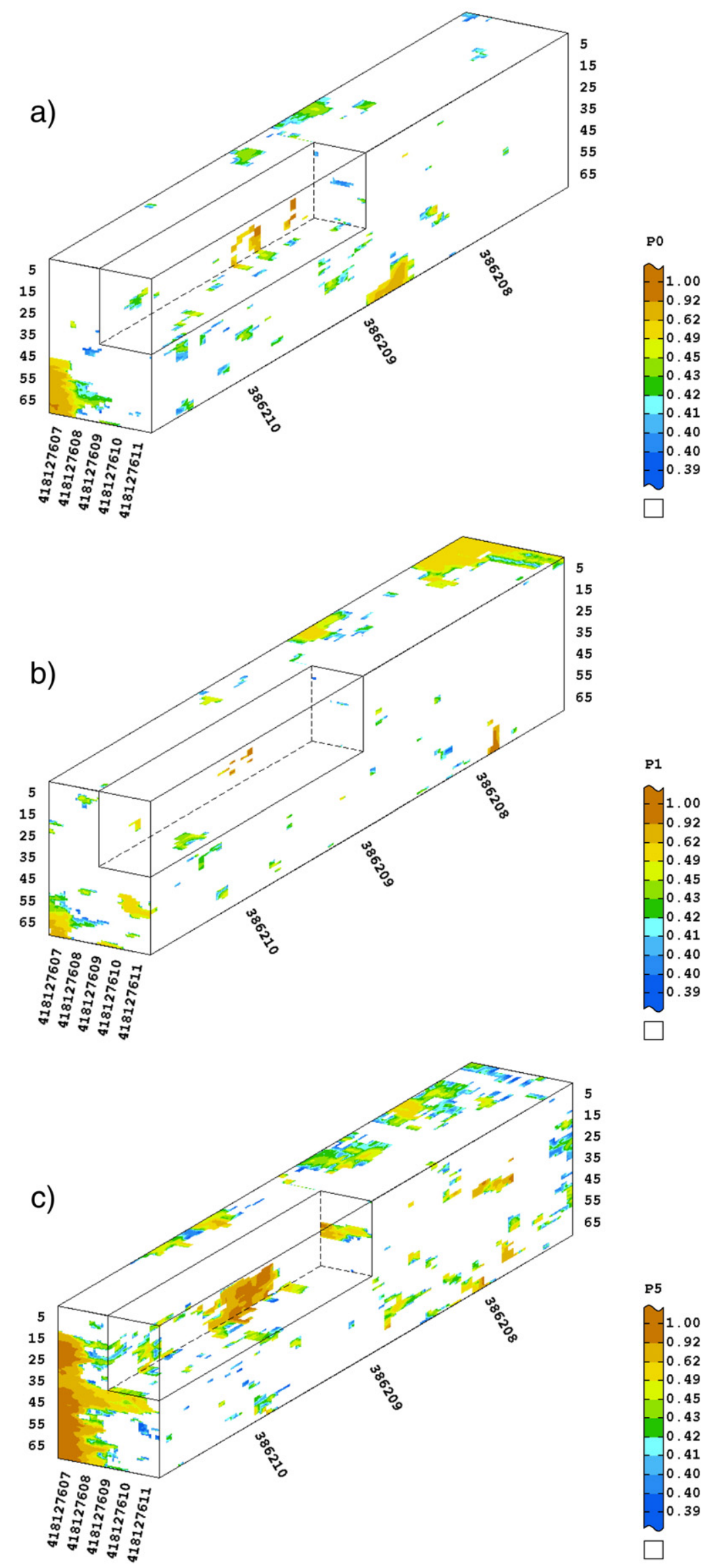
Recently new electronic penetrometers have been designed, in order to map also other soil characteristics such as soil texture, moisture, bulk electric conductivity and even real time subsurface imagery (Rooney and Lowery, 2000; Rooney et al., 2000; Drummond et al., 2000). These advanced electronic penetrometers with a built-in GPS, used together with a GIS and geostatistical methods, could allow an easy and efficient real time mapping of soil characteristics. Moreover, these instruments could allow the measurement of soil characteristics affected by an error estimated by using previous calibration functions, in order to correctly map these characteristics.

The successful combination of an electronic penetrometer, a GPS, a GIS and geostatistical methods allows to rapidly "map" the soil compaction and associate it with other spatially fundamental information such as those deriving from yield maps or remote sensing images.

\section{Acknowledgements}

The authors gratefully acknowledge the financial support of the Italian Ministry of Instruction, University and Research through the PRIN 2002-2003 fund, coordinated by Prof. Febo, and ex $60 \%$ fund, coordinated by Prof. Carrara.

\section{References}

Atwell, B.J., 1990. The effect of compaction on wheat during early tillering: I. Growth, development and root structure. New Phytologist 115, 29-35.

Bakker, D.M., Davis, R.J., 1995. Soil deformation observations in a Vertisol under field traffic. Australian Journal of Soil Research 33, 817-832.

Balbuena, R.H., Terminiello, A.M., Claverie, J.A., Casado, J.P., Marlats, R., 2000. Soil compaction by forestry harvester operation. Evolution of physical properties. Revista Brasileira de Engenharia Agricola e Ambiental 4, 453-459.

Basso, B., Sartori, L., Bertocco, M., Oliviero, G., 2003. Evaluation of variable depth tillage: economic aspect and simulation of long term effects on soil organic matter and soil physical properties. In: Stafford, J., Werner, A. (Eds.), Precision Agriculture. Wageningen Academic Publishers, pp. 61-67.

Bathke, G.R., Cassel, D.K., Hargrove, W.L., Porter, P.M., 1992. Subsurface compaction reduces the root and shoot growth and grain yield of wheat. Soil Science 154, 316-328.

Bengough, A.G., Mullins, C.E., 1990. Mechanical impedance to root growth: a review of experimental techniques and root growth responses. Journal of Soil Science 41, 341-358.

Bennie, A.T.P., 1991. Growth and mechanical impedance. In: Waisel, Y., Eshel, A., Kafkafi, U. (Eds.), Plant Roots: The Hidden Half, (1st edition). Marcel Dekker, New York, NY, USA.

Burgess, T.M., Webster, R., 1980. Optimal interpolation and isarithmic mapping of soil properties. I. The semi-variogram and punctual kriging. Journal of Soil Science 31, 315-331.

Carrara, M., Comparetti, A., Febo, P., Morello, G., Orlando, S., 2003. Mapping soil compaction measuring cone penetrometer resistance. In: Werner, A., Jarfe, A. (Eds.), Book of Abstracts of the 4th European Conference on Precision Agriculture. 15-19 June, Berlin, Germany. Wageningen Academic Publishers, The Netherlands, p. 176.

Carrara, M., Castrignanò, A., Comparetti, A., Febo, P., Orlando, S., 2005. Multivariate geostatistics for assessing and predicting soil compaction. Proceedings of the 5th European Conference on Precision Agriculture. 9-12 June, Uppsala, Sweden, pp. 723-730.

Castrignanò, A., Maiorana, M., Fornaro, F., 2003. Using regionalised variables to assess field-scale spatiotemporal variability of soil impedance for different tillage management. Biosystems Engineering 85 (3), 381-392.
Castrignanò, A., Maiorana, M., Fornaro, F., Lopez, N., 2001. Mapping spatial and temporal variability of cone resistance data in an Italian field cropped to durum wheat. In: Grenier, G., Blackmore, S. (Eds.), Proceedings of the 3rd European Conference on Precision Agriculture. 18-21 June, Montpellier, France, Agro Montpellier, Ecole de Nationale Supérieure Agronomique Montpellier, pp. 355-359.

Castrignanò, A., Maiorana, M., Fornaro, F., Lopez, N., 2002a. Spatial and temporal variability of soil strength and its change over time in a durum wheat field in Southern Italy. Soil \& Tillage Research 65 (1), 95-108.

Castrignanò, A., Lopez, N., Prudenzano, M., Steduto, P., 2002b. Estimation or stochastic simulation in soil science? In: Zdruli, P., Steduto, P., Kapur, S. (Eds.), Selected Papers of the 7th International Meeting on Soils with Mediterranean Type of Climate. September 2001, Bari, Italy. Option Méditerranéennes, Series A: Mediterranean Seminars, vol. 50. CIHEAM, Paris, France, pp. 167-182.

Chiles, J.P., Delfiner, P., 1999. Geostatistics. Modelling Spatial Uncertainty. A Wiley-Interscience Publication, New York, NY, USA.

Deutsch, C.V., Journel, A.G., 1998. GSLIB: Geostatistical Software Library and User's Guide. Oxford University Press, New York, NY, USA.

Drummond, P.E., Christy, C.D., Lund, E.D., 2000. Using an automated penetrometer and soil EC probe to characterise the rooting zone. Proceedings of the 5th International Conference on Precision Agriculture. 20-24 July 2000, Bloominghton, MN, USA. ASA-CSSA-SSSA, Madison, WI, USA.

Febo, P., Pessina, D., 2002. Ground pressures exerted by agricultural machines. In: Pagliai, M., Jones, R. (Eds.), Sustainable Land Management Environmental Protection: A Soil Physical Approach. Catena Verlag Gmbh, Reiskirchen, Germany, pp. 339-350.

Febo, P., Pagliai, M., Pessina, D., 1998. Occurrence, experiences and research on soil compaction in Italy. Proceedings of the 1st Workshop of the Concerted Action on Subsoil Compaction "Experiences with the Impact and Prevention of Subsoil Compaction in the European Community". Wageningen, The Netherlands, pp. 96-107.

Goovaerts, P., 1997. Geostatistics for Natural Resources Evaluation. Oxford University Press, New York, NY, USA.

Goovaerts, P., 1999. Geostatistics in soil science: state-of-the-art and perspectives. Geoderma 89, 1-45.

Goovaerts, P., 2001. Geostatistical modelling of uncertainty in soil science. Geoderma 103 (1-2), 3-26.

Goovaerts, P., Chiang, C., 1993. Temporal persistence of spatial patterns for mineralizable nitrogen and selected soil properties. Soil Science Society of America Journal 57 (2), 372-381.

Heinonen, M., Alakukku, L., Aura, E., 2002. Effects of reduced tillage and light tractor traffic on the growth and yield of oats (Avena sativa). In: Pagliai, M., Jones, R. (Eds.), Sustainable Land Management - Environmental Protection: A Soil Physical Approach. Catena Verlag Gmbh, Reiskirchen, Germany, pp. 367-378.

Jorajuria, D., Draghi, L., 2000. Sobrecompactacion del suelo agricola. Parte I: influencia diferencial del peso y del numero de pasadas. Revista Brasileira de Engenharia Agricola e Ambiental 4, 445-452.

Journel, A.G., 1983. Non-parametric estimation of spatial distribution. Mathematical Geology 15, 445-468.

Lajaunie, C., Béhaxétéguy, J.P., 1989. Elaboration d'un programme d'ajustement semi-automatique d'un modèle de coregionalisation - Théorie. Technical report N21/89/G. ENSMP, Paris, France, pp. 6.

Mouazen, A.M., Ramon, H., De Baerdemaeker, J., 2001. On-line detection of soil compaction distribution based on finite element modelling procedure. Proceedings of the 3rd European Conference on Precision Agriculture. 18-21 June, Montpellier, France, Agro Montpellier, Ecole Nationale Supérieure Agronomique de Montpellier, pp. 455-460.

O'Sullivan, M.F., Dikson, J.W., Campbell, D.J., 1987. Interpretation and presentation of cone resistance data in tillage and traffic studies. Journal of Soil Science 38, 137-148.

Oussible, M., Crookston, R.K., Larson, W.E., 1992. Subsurface compaction reduces the root and shoot growth and grain yield of wheat. Agronomy Journal 84, 34-38.

Pagliai, M., Marsili, A., Servadio, P., Vignozzi, N., Pellegrini, S., 2000. Changes of some physical properties of a clay soil following the passage of 
rubber tracked and wheeled tractors of medium power. In: Arvidsson, J., van den Akker, J.J.H., Horn, R. (Eds.), Experiences with the impact and prevention of subsoil compaction in the European Community. SLU REPRO 2000, pp. 131-144.

Richard, G., Boizard, H., Roger-Estrade, J., Boiffin, J., Guérif, J., 1999. Field study of soil compaction due to traffic in Northern France: pore space and morphological analysis of the compacted zone. Soil \& Tillage Research 51, $151-160$.

Rooney, D.J., Lowery, B., 2000. A profile cone penetrometer for mapping soil horizons. Soil Science Society of America Journal 64, 2136-2139.

Rooney, D.J., Lieberman, S.H., Norman, J.M., Scarpace, F.L., 2000. Imaging the colour characteristics of the soil environment. Proceedings of American Society of Photogrammetry and Remote Sensing. May, Washington, DC, USA.
Seker, C., Isildar, A.A., 2000. Effects of wheel traffic porosity and compaction of soil. Turkish Journal of Agriculture and Forestry 24, 71-77.

Taylor, H.M., Robertson, G.M., Parker Jr., J.J., 1966. Soil strength-root penetration relations for medium-to-coarse-textured soil materials. Soil Science 102, 18-22.

USDA, 1998. Soil taxonomy: Keys to Soil Taxonomy, Sixth Edition.

Wackernagel, H., 2003. Multivariate Geostatistics: an introduction with Applications. Springer-Verlag, Berlin. 